\title{
The Research of Relationship Between Innovation Output and Employment
}

\author{
Ke Gao ${ }^{1}$, Nan $\mathrm{Bai}^{2}$, Kun Huang ${ }^{3}$ \\ ${ }^{1}$ The School of Finance and Taxation, Central University of Finance and Economics, Beijing, P.R.China \\ ${ }^{2}$ The School of Finance, Renmin University of China, Beijing, P.R.China \\ ${ }^{3}$ PBC School of Finance, Tsinghua University, Beijing, P.R.China
}

Email address:

gkfly@126.com (Ke Gao), 99536157@qq.com (Nan Bai), huangkun3653785@126.com (Kun Huang)

\section{To cite this article:}

Ke Gao, Nan Bai, Kun Huang. The Research of Relationship Between Innovation Output and Employment. Journal of World Economic Research. Vol. 6, No. 2, 2017, pp. 23-26. doi: 10.11648/j.jwer.20170602.12

Received: December 20, 2016; Accepted: March 23, 2017; Published: March 29, 2017

\begin{abstract}
This article selects 2000-2015 zhongguancun science park patent license number and annual employment population data to establish the VAR model, and do the empirical analysis on relationships between the zhongguancun science park innovation output and employment. Results show that the high quality labor of zhongguancun science park has a positive role in promoting the growth of innovation output, and the innovation output increase also has a significant role in promoting the employment growth.
\end{abstract}

Keywords: VAR Model, Innovation Output, Employment

\section{Introduction}

Technological innovation is the driving force of economic and social development, the decisive factor to enhance a country's comprehensive strength. Beijing zhongguancun science park innovation ability has been among the best in the country and also has played an important role in promoting our country's independent innovation ability and the comprehensive national strength.

Innovation of science and technology will greatly improve the labor productivity and promote the great development of the productivity, but it is accompanied with the problem that how to solve the relationship between innovation and the employment. Some people think that the faster the pace of scientific and technological innovation is, the less labor the society needs, thus innovation is unfavorable to expand employment, also someone has the view that innovation of science and technology is the opposition of taking the advantage of abundant labor resources. Therefore, making clear the relationship between technological innovation and labor employment, has important practical significance both in theory and practice.

Based on the literature review related to the relationship between the innovation and employment, this paper uses the zhongguancun science park official statistics to do empirical research on the relationship between the innovation output and employment of zhongguancun science park, and get several conclusions.

\section{VAR Model and Empirical Analysis}

A. Definition of Variables and Data Sources

First of all, we need to use variable to define innovation output, in this article, we select the zhongguancun science park patent licenses as a measure of innovative output indicators, the greater its value is, the more innovation output it has, the smaller values mean the less innovation output. In terms of employment, we choose the annual employment population of the zhongguancun science park as a measure, higher numbers indicate better employment situation, smaller numbers indicate worse employment condition. The unit of patent licenses is piece, the unit of the annual employment population is ten thousand person. In order to assure the comparability of data and easy to get smooth sequence and eliminate the possible existence of heteroscedasticity, we take the natural logarithm of the original data, get the two natural logarithm sequences of original data sequence, for LNPAT, 
LNL. The original data of two variables come from the zhongguancun science park annals, zhongguancun science park yearbook, from 2000 to 2015.

B. Unit Root Test (ADF test)
Since VAR model requires variable sequence itself is stationary or same-order single whole sequence, so before modeling, we implement stationarity test on LNPAT sequence and LNL sequence, test results are shown in table 1.

Table 1. Unit root test results.

\begin{tabular}{llllll}
\hline Variable & $(\mathbf{c}, \mathbf{t}, \mathbf{k})$ & ADF test statistic & $\mathbf{5 \%}$ critical values & 1\% critical values \\
\hline LNPAT & $(\mathrm{c}, 0,0)$ & -0.714831 & -3.081002 & -3.959148 \\
$\triangle$ LNPAT & $(0,0,1) *$ & -2.814578 & -1.968430 & -2.740613 \\
LNL & $(\mathrm{c}, 0,0)$ & -2.745088 & -3.144920 & -4.121990 \\
$\triangle$ LNL & $(\mathrm{c}, \mathrm{t}, 1) * *$ & -4.372809 & -3.875302 & -4.992279 & nonstationary \\
\hline
\end{tabular}

Note: the inspection type $(\mathrm{c}, \mathrm{t}, \mathrm{k}), \mathrm{c}$ and $\mathrm{t}$ represent intercept and trend, $\mathrm{k}$ represents the lag order, according to the SC and AIC criterion to determine. $* * *, * *, *$ represent $1 \%$ level, the level of $5 \%$ and $10 \%$ levels significantly.

The results in table 1 show that ADF statistics of variable LNPAT, LNL are smaller than the critical value of the $5 \%$ significant level in the case of a zero-order lag, it means the original sequence has unit root. But ADF statistics of variable LNPAT, LNL are bigger than the critical value of the $5 \%$ significant level in the case of a first-order lag, so $\triangle$ LNPAT, $\triangle \mathrm{LNL}$ are stationary series, eliminate the influence of unit root. Two sequences are first-order single whole, could be used to establish the VAR model.

C. The Establishment of the VAR Model

For patent license number LNPAT and employment population LNL, we build standard VAR model:

$$
\begin{aligned}
& \operatorname{LNPAT}_{t}=a_{10}+\sum_{i=1}^{p} b_{1 i} L N P A T_{t-i}+\sum_{i=1}^{p} c_{1 i} L N L_{t-i}+e_{1 t} \\
& L N L_{t}=a_{20}+\sum_{i=1}^{p} b_{2 i} L N P A T_{t-i}+\sum_{i=1}^{p} c_{2 i} L N L_{t-i}+e_{2 t}
\end{aligned}
$$

Among them, $\mathrm{e}_{1 \mathrm{t}}$ and $\mathrm{e}_{2 \mathrm{t}}$ are random disturbance items.

D. VAR Stability Test

The former unit root test has shown that two selected sequences are same order single whole sequences, so they can be used to build VAR model. The stability of the VAR model requires all the characteristic value of characteristic equation, namely all the root of characteristic equation must be within the unit circle or the opposite all roots of the characteristic equation must be outside the unit circle. Unit root test of the two variables are shown in the following table 2 and figure 1.
Table 2. Roots of Characteristic Polynomial.

\begin{tabular}{ll}
\hline Root & Modulus \\
\hline 0.997906 & 0.997906 \\
-0.485013 & 0.485013 \\
$0.357163-0.218217 \mathrm{i}$ & 0.418550 \\
$0.357163+0.218217 \mathrm{i}$ & 0.418550 \\
\hline
\end{tabular}

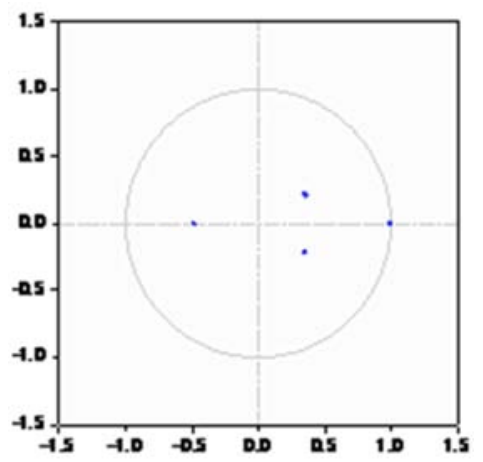

Figure 1. Inverse Roots of AR Characteristic Polynomial.

From the figure 1, we can see that all the root of characteristic equation are within the unit circle so the VAR model is stable.

For the determination of the optimal lag order number, on the one hand, we should consider the AIC, SC minimum standards, on the other hand, we should consider the effect on the stability of the VAR model from different lag order. Because when the lag order $p \geqq 3$, VAR model is not stable, so the optimal lag order number must be within 3 order for selection. After repeated verification, the best lag order $\mathrm{p}$ is 1 . Results by the Eviews8 are shown in table 3:

Table 3. VAR Lag Order Selection Criteria.

\begin{tabular}{lllllll}
\hline Lag & LogL & LR & FPE & AIC & SC & HQ \\
\hline 0 & -8.421930 & NA & 0.015201 & 1.488847 & 1.580141 & 1.480396 \\
1 & 31.94829 & $63.43891^{*}$ & $8.53 \mathrm{e}-05^{*}$ & $-3.706898^{*}$ & $-3.433016^{*}$ & $-3.732251^{*}$ \\
2 & 34.55642 & 3.353312 & 0.000110 & -3.508060 & -3.051590 & -3.550314 \\
\hline
\end{tabular}

According to the constructed VAR model, we deal with data through Eviews8, we can write standard VAR model estimation results as follows:

$$
\begin{aligned}
& \text { LNPAT }=0.712858841992 * \operatorname{LNPAT}(-1)+0.418021425952 * \operatorname{LNL}(-1)+0.829260808821 \\
& \mathrm{LNL}=0.0892471395155 * \operatorname{LNPAT}(-1)+0.818328977783 * \operatorname{LNL}(-1)+0.182898336097
\end{aligned}
$$

Equation (1) show that the employment of lag 1 phase has a significantly positive role in promoting the current number of patent license. When the employment of lag 1 phase changes $1 \%$,it will cause patent license number changes $0.4180 \%$, at 
the same time when the patent license number of lag 1 phase changes $1 \%$,it will cause current patent authorization number to change $0.7129 \%$, which reflects the continuity of the innovation output.

Equation (2) show that the number of patent authorization number of lag 1 phase also have a positive influence on the current employment, when the patent license number of lag 1 issue changes $1 \%$,it will cause the current employment to change $0.0892 \%$, which means the increase of innovation output will absorb more employment to some extent in turn.

E. Impulse Response Analysis

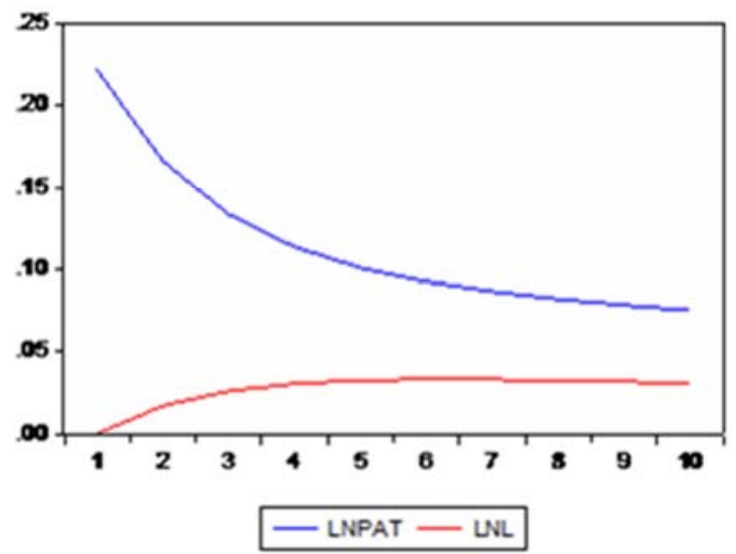

Figure 2. Response of LNPAT to Cholesky One S.D. Innovation.

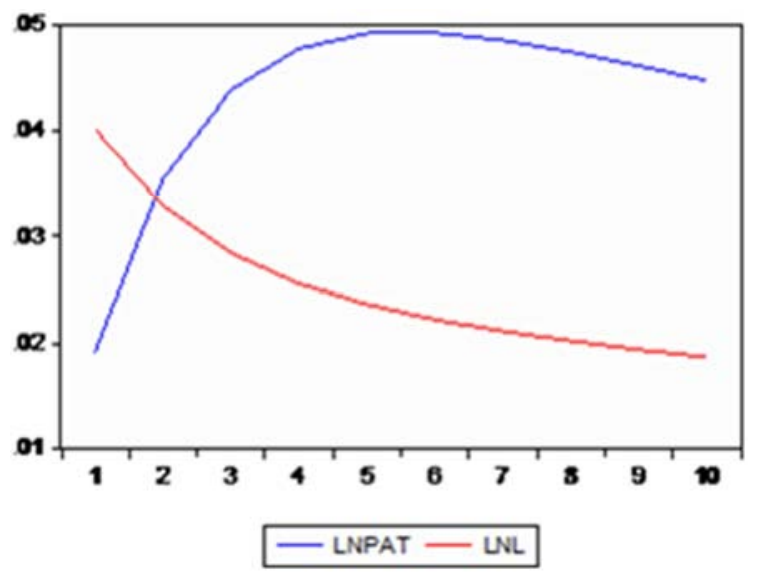

Figure 3. Response of LNL to Cholesky One S.D. Innovation.

Impulse response function describes an endogenous variable response to the impact of changes in one unit from another endogenous variables, provide information about the positive and negative direction, adjusted delay and stable process when the system is attacked. In order to further reveal the dynamic relationship between zhongguancun innovation output and employment, this paper uses Eviews8 software to respectively calculate the zhongguancun innovation output and employment impulse response when there is a standard deviation change. Specific results are shown in figure 2, horizontal axis shows follow-up periods of response function, the vertical axis represents response degree of the impact from independent variables to dependent variables.

Figure 2 reflects LNPAT dynamic response of a standard deviation impact from endogenous variables: LNPAT response to its own a standard deviation impact is showing a trend of rapid decay with the increase of $\mathrm{n}$ per, but the value has been positive, it verifies the accumulation of innovation output is one of the important factors affecting continuous innovation. And when there is one standard deviation impact from the LNL, LNPAT will generate strong reaction immediately at early stage and reach a certain height nearly at the third period, then keep the level for a long time, do not appear relatively obvious jump or steep fall. It indicates that human resources has always played an important role in the zhongguancun innovation output. The reason why in 2000-2003, there is a spurt, I think there is a certain relationship with the implementation of the national High-tech zone "second pioneering" strategy.

Figure 3 reflects LNL dynamic response of a standard deviation impact from endogenous variables: LNL response to its own a standard deviation impact is showing a trend of slow decay with the increase of nper, suggesting that early human resource accumulation will crowd out the new human resources, but its value has been positive, which means it still be able to absorb employment. For one standard deviation impact from the LNPAT, LNL will generate strong reaction immediately in the early days, which shows a tendency of rapid growth, and reaches the maximum at about 6 phase, then presents a decreasing trend. This shows that in a few years after the implementation of the National High-tech Zone "second pioneering" strategy in 2001, the increase of innovation output played a large role in absorbing employment and talents. And in 2008, due to the financial crisis and the global economic downturn, zhongguancun innovation output had also been affected, the drive of jobs began to decline.

F. Variance Decomposition

Variance decomposition is based on the analysis of contribution of each structure impact on endogenous variable, it is used to further evaluate the importance of different structural shocks.

In order to further analyze contribution of each structure impact on endogenous variable, now with the help of variance decomposition, we investigates the dynamic relationship of employment and innovation output. From figure 4, the LNPAT variance decomposition, we see that LNPAT overall volatility is not very big, presents the approximate linear slow decline, from 1 to 10 , fall by $5 \%$, the contribution in 10 phase is about $95 \%$, this shows that patent license number has a strong explanatory power on its own ; The contribution of the human resources impact on patent output is about $5 \%$.

From figure 5, the LNL variance decomposition, employment changes have a big contribution on its own at the beginning, the contribution of innovation output on employment change is small, but the influence of employment itself has gradually decreases, the influence of innovation output has increasing trend. In the 10th, the employment contribution of their own impact reduces to about $25 \%$, innovation output impact contribution increases to about $75 \%$. 


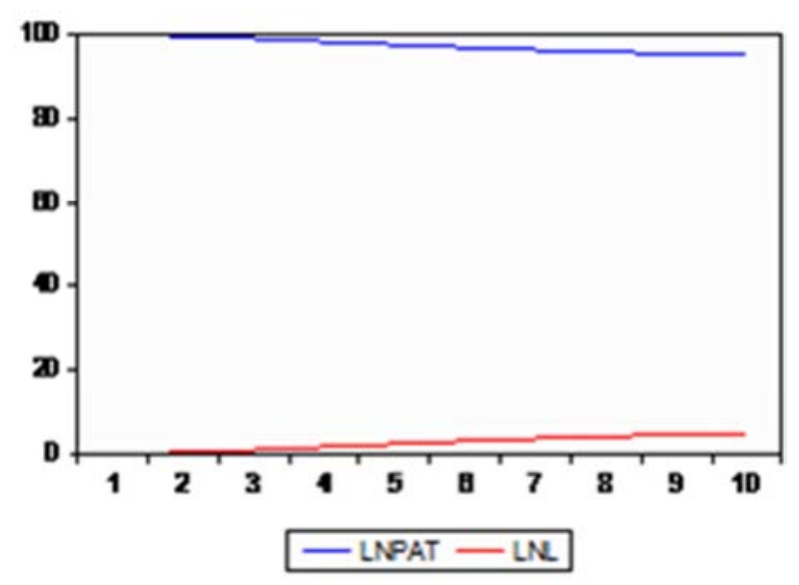

Figure 4. Variance Decomposition of LNPAT.

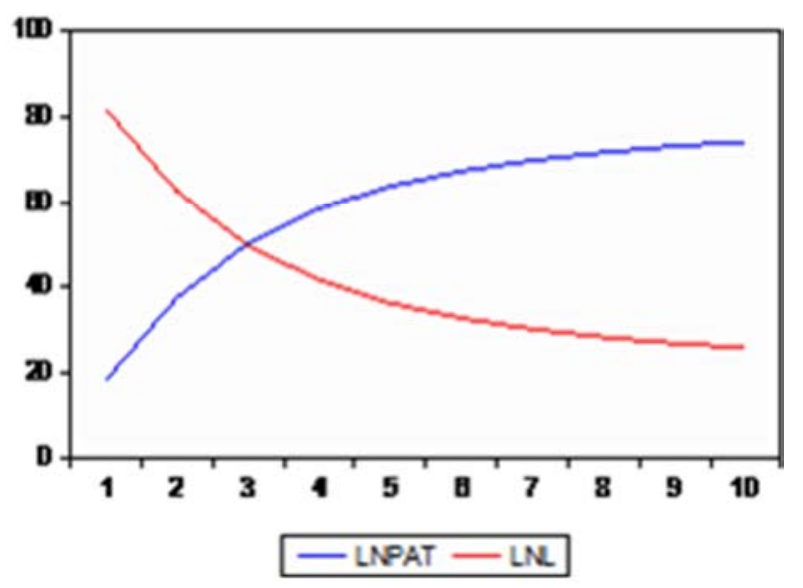

Figure 5. Variance Decomposition of LNL.

\section{Conclusion and Suggestion}

With the VAR model, we analyze dynamic relationships of zhongguancun innovation output and employment, this paper get the following conclusion:

The increase of zhongguancun employment has a significant role in promoting innovation output, this is because the zhongguancun science park is a gathering area for independent innovation, its absorption of employees tend to have higher education level and good quality. This inspires us to attract more high level talents to zhongguancun in order to provide safeguard for the continuous innovation of zhongguancun.

The increase of zhongguancun innovation output has a positive role in promoting absorbing employment, and its contribution tends to rise gradually. This is because the innovation output increase can stimulate innovation entrepreneurship, create more new demand and jobs, and make the zhongguancun science park become the engine of creating more employment opportunities. The empirical results enlighten us to adhere to the road of innovation driven development continuously. Through the reform of supply side, we can create more employment opportunities, then enter into the virtuous circle "innovation, employment, innovation".

\section{References}

[1] ChengYuLin. Science and technology innovation and labor employment relationship study [J]. Journal of qiqihar university (philosophy and social sciences edition), 2002 01:25 to 28 .

[2] Zhongguancun science park management committee. Annals of zhongguancun. [M]. Beijing press, 2008.

[3] Zhongguancun science park management committee. Yearbook of zhongguancun. [M]. Beijing press, 2008-2015.

[4] Tie-Mei Gao. Econometric analysis method and modeling [M]. Beijing: tsinghua university press, 2007.

[5] Granger C. W. J. and Newbold P. (1974), Spurious Regressions in Econometrics [J]. Journal of Econometrics, 2,111- 20.

[6] Zhang Qing. Dynamic analysis of the relationship of FDI and GDP in anhui province based on VAR model [J]. Journal of henan business college, 2010 practices: 13 to 16 .

[7] Plum nai. Advanced econometric [M]. Beijing: tsinghua university press, 2000. 9.

[8] Rockafellar R T, Uryasev S. Optimization of Conditional Value-At-Risk [J]. Journal of Risk, 2000, 29(1):1071-1074.

[9] Eickmeier S, Ng T. How do US credit supply shocks propagate internationally? A GVAR approach [J]. European Economic Review, 2015, 74:128-145.

[10] Hubrich K, Tetlow R J. Financial stress and economic dynamics: The transmission of crises [J]. Journal of Monetary Economics, 2015, 70:100-115.

[11] Weale M, Wieladek T. What are the macroeconomic effects of asset purchases? [J]. Journal of Monetary Economics, 2016, 79(10):81-93.

[12] Cacciatore M, Fiori G. The macroeconomic effects of goods and labor markets deregulation $[\mathrm{J}]$. Review of Economic Dynamics, 2016, 20: 1-24. 